\title{
Didactic and Psychodidactic Features of Forming Universal Learning Action Subject
}

\author{
Victor Panov \\ Laboratory of ecopsychology of development and \\ psychodidactics \\ Psychological Institute of Russian Academy of Education \\ 4 building, 9 Mokhovaya Street, Moscow, 125009, Russia \\ E-mail: ecovip@mail.ru
}

\author{
Irina Plaksina \\ Department of pedagogics \\ Vladimir State University named after Aleksander \\ Grigoryevich and Nikolay Grigoryevich Stoletovs \\ 195-52 Lakina Street, Vladimir, 600028, Russia \\ E-mail: irinaplx@mail.ru
}

\begin{abstract}
Article represents methodological analysis of didactic and psychodidactic premises using for development of universal learning actions and learner's subject qualities needed for this. For purposeful forming of learner's subjectness, ecopsychologic (ontologic) model of subjectness becoming, is expected to use. It includes types of interactions between pedagogue and learners. This model is elaborated without basis on substantive content of learning theme and learning actions. Because of this, it can serve as psychodidactic basis for development of subject qualities providing with successful forming of universal learning actions and achieving metasubstantive results in scholar learning.
\end{abstract}

Keywords-universal learning actions; learners; subject; subjectness; didactic; psychodidactic paradigm; becoming of subjectness; stages; ecopsychologic model; universal (topologic) character; ecopsychologic interactions

\section{INTRODUCTION}

The main vector of the Russian education development in the last decade is the transition to the competence-based educational paradigm, represented in the form of the Federal State Educational Standard. For the actual implementation of such a transition, there should be a shift in training with the formation of the subject skills of the students in the direction of development of the interdisciplinary universal learning activities. This means, there should also be a change to the traditional goals of schooling. "The aim of education is the general cultural, personal, and cognitive development of the students, allowing such a key competence as an ability to study" [1, P. 3]. Therefore, subjects' content and educational actions of a specific academic subject, must turn from the goals of education into pedagogical means of developing the students' ability to be subjects of universal learning activities. In turn, this means a change of priority in the use of didactic and psychological preconditions for forming the learning technologies. Namely, psychological goals should be used as the initial assumptions, i.e. the psychological conditions for the development of the ability to be a subject of universal learning activities. At the same time, didactic background (content of the educational materials etc.) should be used as a

Work is performed with maintenance of the RFBR (RFH), project № 17-06-00871. mean to achieve this goal.

As was shown earlier [2, 3], such a change in the ration of didactic and psychological prerequisites in education leads to a shift from a didactic paradigm of studying to a psychological-didactic (psychodidactic) one. Thus, a number of methodological problems emerge.

On the didactic level, the issue of the subjectivity development in education is due to the methodological framework of the didactic paradigm of modern education. The fact is, this paradigm's presupposition lies within the subject's content of an academic discipline, and, accordingly, in the subject-specific skills (subjective learning activities), providing the digestion of the discipline's knowledge and not the subjective qualities of students. As a result, the formation of the subjectness of a student (as a subject of learning activities) in the framework of the didactic paradigm is determined, firstly, by the content of an academic subject: various academic subjects mean various subjective qualities. Figuratively speaking, the learning is built "wrong end foremost", i.e. based on what the subjective learning activities should be, instead of what the psychological conditions should be to develop the ability to be the subject of those learning activities. Secondly, the development of the subjective qualities under such learning is not purposeful but spontaneous, so as to specify the way of acting, but not the own logic of developing the subjective qualities necessary to master the action. As an example, we may provide a didactic method, when the same task is presented to students in different forms so that they have a generalized way of solving it. Speaking of meta-subject results of the learning activities, which involve the ability of the students to be the subjects of universal learning activities, their formation would be more spontaneous, accidental.

For the formation of subjectness of a student to be focused, the initial base for the construction of educational technologies is to be found in the psychological models of the subjective qualities, that are necessary to be a subject of not only objective but also of the universal learning activities. 


\section{ON THE CONCEPTS OF "PSYCHODIDACTICS" AND "PSYCHODYDACTICAL"}

The concepts of "psychodidactics" and "psychodidactical" are used in two senses.

Originally the concept was used to determine the psychological-didactic (psychodidactics) paradigm used to construct such learning technologies, based on psychological principles, regularities, and peculiarities of psychological development of the conditions and means of learning [4]. One example is the system of the developing education of "D.B. Elconin - V.V. Davydov" based on the principles of the age periodization (the leading type of activity for the elementary students is the learning activity), the unity of activity and development, the jointly-distributed activity, and the concept of theoretical thinking (generalization on the theoretical type). Under the conditions of the said system, these principles served as the original basis for determining (selection and the corresponding transformation) of the content and methods of learning of the basic elementary school's disciplines. There are other examples of the developing learning technologies built on other psychological grounds (N.A. Menchinskaya, N.F. Talyzina, V.S. Bibler and others).

The necessary emergence of the psychodidactic paradigm is due to the fact that traditional learning technologies provide the development of a student on the principle of accretion of the new knowledge and skills, thus facilitating the reproductive activity of a student's consciousness (perception of learning material - reproduction of learning material). Therefore, the psychological peculiarities of the development of the subjectness are beyond the learning technology (its content and method). The reason for this is of a methodological nature and is manifested in the fact that the learning technologies in this approach reproduce the logic and content of the relevant academic field, but not the own logic of mental development. Therefore, the traditional approach is defined as the didactic paradigm [5].

Currently, the definition "psychodidactics" - and this is its second meaning - also represents a specific area of a mutual overlap of modern psychology and didactics as an interdisciplinary direction being proactively formed over the last decade at the intersection of psychology and didactics. A distinctive feature of this direction is the use of psychological principles, regularities, and peculiarities as a basis to:

- Examine and develop the curricula and learning technologies;

- Develop the textbooks and learning guides;

- Design and examine the educational environment;

- Develop the psychological aspects of the management of the nourishing educational institutions:

- Examine the quality of education.

In this case under "psychodidactics" we understand the intersection area of the issues of psychology (psychology of development, pedagogical psychology, psychology of education) and didactics relating to educational technologies, conditions and systems. The original theoretical basis for psychodidactics in this sense is the thesis that the effectiveness of education depends on the extent to which the learning technologies and systems meet not only the didactic content of an academic, subject, but also the psychological characteristics and regularities of the development of the students.

Psychological subject of psychodidactics are represented by psychological peculiarities, patterns and principles of development, used as the initial basis for the expertise, design and construction of educational systems and their components.

The most frequently the principles of age periodization, unity of activities, education and development, the zones of proximal development, dialogue (communicative interaction in jointly-distributed activities), reflection, as well as various theories of cognition, etc. are used as the aforementioned psychological basis.

\section{CONCEPT OF DEVELOPMENT OF UNIVERSAL LEARNING ACTION AND OTHER MODELS OF LEARNING}

As it is known, a system-activity approach was developed as a psychological basis for the nurturing of the universal learning activities [6]. In this approach, the concept of the systematic universal learning activities is introduced as part of the personal, regulatory, cognitive, and communicative actions, specified in the relevant skills. So, for example, the personal universal learning activities are the activities for self-determination, self-education, the ability to highlight the moral aspect of conduct, the determination of social roles, etc.; the communicative universal learning activities - "the ability to listen and to engage in dialogue, to participate in a collective discussion of the problems, to integrate into a group of peers and to build productive interaction and cooperation with peers and adults" [ibid, P. 108]. However, it is not specified, how a teacher should do this, except that "the joint learning activities create the meaningful basis for the transition of a student from the practical to the cognitive attitude to the world, being the ground of formation of conscious self-regulation and the subjectness of the activity" [ibid, P. 106] and that "when creating the model of the ties of the universal learning activities it is necessary to proceed from the general understanding of the developmental age" [ibid, P. 108]. From these quotations, it is easy to conclude that the definition of subjective qualities is necessary for the formation of universal learning activities and is carried out basing on the academic subject's content required and caused by it. In the end, our own (mental) logic of the formation of the subjective qualities that make up the structure of the universal learning activities remains closed by a veil of subjective content of the personal, regulative, cognitive, and other skills.

It is no coincidence because we are dealing with a common methodological feature of the definition of the stages of formation of mental activities, including in learning. 
Let us use an example a well-known concept of P.Ya. Galperin about the gradual formation of mental activity, according to which the simulation of a specific learning situation has several stages [7]. Another example is a technology by David Kolb, which is a cyclical passage of certain stages, including the reflection on acquired knowledge and skills [8]. The practice of interaction, exchange of experience, development of personal and shared group relations to the various life and learning situations and methods of acting in them, are the essence of the interactive learning technologies, used not only by D. Kolb but also by the other pedagogues, including the Russian teachers [cf. 9, $10]$.

However, the successful usage of interactive learning technologies is hindered by the fact that the training of the teachers is focused largely on the academic subjects' content. So, the teachers are more oriented on transmitting the content of the academic subjects, than on the establishment of the communicative interaction in a classroom as a prerequisite for interactive learning technologies [11]. As a result, the development of the ability to be a subject of universal learning activities is being designed by the pedagogues within the didactic paradigm framework, i.e. in retrospect, when the development of universal learning activities is considered, figuratively speaking, from "the end" and not from "the beginning".

Reverting to the systematic-activity approach, it is necessary to note that methodologically it is characterized by the same methodological features that were discussed in relation to the didactic approach. Let us discuss this in detail.

The systematic-activity approach is the integration of the basic positions of various psychological approaches to the development through learning [12]. We are talking about a cultural-historical approach, an activity approach, a subjective approach, and a systematic approach. Despite the differences in the methodological foundations of each of these approaches, in the framework of systematic-activity approach, they share a commitment to the development of subjective qualities of a student, providing interdisciplinary skills in the cognitive, personal, regulatory, and communicative spheres of his development. Therefore, it is assumed, that from a psychological standpoint, for the development of a school student's subjectness it is enough to take a psychological model of the universal learning activities, developed in the framework of systematic-activity approach [ibid], and to clothe it into a didactic form of a relevant discipline. Yet, here we encounter the aforementioned methodological problem of formation of the subject's learning activities based on a substantive content of an academic discipline and on a psychological level. Namely, the own (psychological) logic of the formation of the subjectness once again remains a closed content ("veil") of the subjective content of the personal, regulatory, cognitive, and communicative skills.

It would seem that from the psychodidactic point of view, the described didactic problem is solved quite simply. One may need to use a psychological model of the subjectness development and to "dress" it into the form of universal learning activities and didactic materials on the academic subject. But here we encounter one more methodological problem, also on a psychological level. The fact is that the definition and comprehension of the subject as a mental and psychological reality doesn't cause any ambiguity in the modern days: a subject is a carrier (the implementer) of activity. But the subjectness as a set of subjective qualities is understood and defined differently by different authors, depending on an individual, is considered a subject of "something" (e.g., personality and forms of its existence, activity, and its types, etc.) [13,14].

\section{ECOPSYCHOLOGICAL MODEL OF THE SUBJECTNESS FORMATION AS THE BASIS OF FORMATION OF UNIVERSAL LEARNING ACTIVITIES}

So, the formation of the universal learning activities and their subject raises the question about the need for a psychological model of subjectness development, which would allow to purposefully develop the universal learning activities and the necessary subjective traits. The previously developed ecopsychological (ontological) model of the subjectness formation is encouraged to be used as a model of the subjectness development [15]. According to the scheme, the subjectness formation is to be considered in a continuum "a subject of spontaneous mental activity - a subject of voluntary action" as a process of gradual transformation of "a subject of a spontaneous mental activity" into "a subject of voluntary action". An individual (a student) passes the following stages in the development of subjectness traits:

- A subject of needs (motivation) in the mastering of learning sample activity;

- A subject of perception of a sample activity - "an observer";

- A subject of imitation (reproductive performance without arbitrary regulation) - "an apprentice";

- A subject of arbitrary execution of a sample activity with an external regulation of the correctness of the implementation (most often performed by a teacher) - "a learner";

- A subject of arbitrary execution of a sample activity with an independent arbitrary regulation of a correctness of the implementation - "a master";

- A subject of the exteriorization of the function of the regulation of the correctness of the implementation of a sample activity, performed by some other individual - "pedagogue", "coach", "expert";

- A subject of productive (creative) development, when a sample activity turns from the object of assimilation into the means of development of the new, more complex actions, or for the creative expression - "a creator".

The suggested theoretical model of the formation of a subject and his activity transformation is an ideal one. In reality, the mentioned stages of subjectness development 
overlap each other, and formation of a single stage may outpace the development of the others.

It is important to add, that the implementation of this model of the subjectness formation requires from a pedagogue the ability to build different types of communicative interaction among the subject of the educational process. Within the ecopsychological approach to the psychological evolution, there are six basic types of interaction among the components of relations "an individual - educational environment" according to the role position of the subjects of the educational environment [16, 17]:

- Object-object, when interaction is purely abstract, formal and is characterized by passivity/objectivity of both parties. Consequently, it cannot be a condition for the subjectness formation of students and pedagogues;

- Object-subject, when a student complies with pedagogic influence. Student's subjectness, in this case is reactive and reproductive in nature and therefore, not undergoes development, but is rather being formed under the pedagogue's influence. Therefore, it is appropriate to refer to this type of interaction as to "pedagogical impact";

- Subject-object, when a pedagogue is constrained to comply with the students' influence. Yet as this type of the students' activity is reproductive (repetition of things, students already know), the development of subjectness in terms of universal learning activities is next to impossible;

- Subject-subject type of interaction is described by the activity from both a student and a pedagogue. However, it should be aimed at collaboration and cooperation or, vice versa, at a destructive, conflict cooperation. In this regard, the subject-subject type of interaction is divided into three types: a) isolated subject type, when cooperation between a student and a pedagogue is destructive, confrontational, not respecting the subjectness of each other; b) sharing subject type, when cooperation between a student and a pedagogue is subordinated to a shared goal, so it is expedient to talk about "pedagogical cooperation" and not about "pedagogical cooperation"; c) generating subject type of interaction in the "student - pedagogue (educational environment)" system is indicative for those situations, when an interaction between a "student" and a "pedagogue" is also subordinated to a shared goal, but it also demands an association into a "subjective community". That is why a "generating" meaning of the generating subject type of interaction is in the production of the subjectness of the very "student - pedagogue (educational environment)" system itself, which is turning into an aggregate (ontological) subject, brood by some other subjectness of each of the components [18].

\section{CONCLUSION}

Easy to notice that the development of the ecopsychological model of the subjectness development in the educational process is not based on the content of an academic subject and learning activities. Due to that, the model has a universal (topological) character. That is why it can serve as a psychodidactic foundation for the development of the subjective qualities that ensure the successful formation of universal learning activities and the achievement of meta subject results at schools.

However, the implementation of the scheme will require the organization of an intersubject interaction in the "student - pedagogue" system in accordance with ecopsychological types of interaction: object-object, subject-object, objectsubject, isolated subject, generating subject and sharing subject. Their usage will allow providing the unity of internalization and exteriorization of the development of executive and regulatory components of the learning activities at different stages of subjectness development. In turn, it will require a pedagogue not only substantive knowledge on a subject but also proficiency in communication skills in order to manage the necessary types of interaction among the students.

It is clear that the next step of this research should be empirical testing of the possibility of usage of the ecopsychological model of the subjectness development as a psychodidactic foundation for the development of subjective qualities among the students in the process of their mastering of the universal learning activities.

\section{REFERENCES}

[1] How to project universal learning actions in primary school: from action to idea: aim for teacher / A.G. Asmolov, G.V. Burmenskaya, I.A. Volodarskaya and others.]; under edition of A.G. Asmolov. M.: Prosveschenie, 2008.

[2] Davydov V.V. Theory of developing training. - M.: Intor, 1996.

[3] Panov V.I. Psychodidactics of educational systems: theory and practice. - SPb.: PITER, 2007.

[4] Davydov V.V. Theory of developing training. - M.: Intor, 1996.

[5] Panov V.I. Psychodidactics of educational systems: theory and practice. - SPb.: PITER, 2007.

[6] Projecting universal learning actions in high school /A.G. Asmolov, G.V. Burmenskaya, I.A. Volodarskaya, O.A. Karabanova, S.V. Molchanov, N.G. Salmina // National psychological magazine, № 1(5). 2011. P.104-110.

[7] Psychological and pedagogical maintenance in implementation of innovational educational programs / Under edition of Yu.P. Zinchenko, I.A. Volodarskaya. - M.: Publishing office of the MSU, 2007. P.35-36

[8] Kolb D. Experiential learning: Experience as the source of learning and development. - Englewood Cliffs: Prentice-Hall, 1984

[9] Davydov V.V. Theory of developing training. - M.: Intor, 1996.

[10] Shumakova N.B. Learning and development of talented children. M. Publishing office of the MPSI; Voronezh: MODEK. 2004.

[11] Panfilova A.P. Interaction between participants of educational process: learning book for bachelors / A.P. Panfilova, A.V. Dolmatov under edition of A.P. Panfilova. - M.: Yurayt Publishing Office, 2016.

[12] Asmolov A.G. Projecting universal learning actions in high school /A.G. Asmolov, G.V. Burmenskaya, I.A. Volodarskaya, O.A 
Karabanova, S.V. Molchanov, N.G. Salmina // National psychological magazine, №1(5). 2011. P.104-110.

[13] Selezneva M.V. Comparative analysis of terms "subject" and "subjectness" in foreign psychology // Messenger of the RUDN, 2015, №2. P. 47-53.

[14] Panov V.I. Ecopsychology: Paradigmal search. - M.; SPb.: Psychological Institute of the RAS; Nestor-Istoriya, 2014.

[15] Ibid.

[16] Panov V.I. Psychodidactics of educational systems: theory and practice. - SPb.: PITER, 2007.

[17] Panov V.I. Ecopsychology: Paradigmal search. - M.; SPb.: Psychological Institute of the RAS; Nestor-Istoriya, 2014.

[18] Panov V.I., Plaksina I.V. Characteristics of pedagogical subjectness // Messenger of the V1SU, 2016, № 25 (44). P. 86-96. 